\title{
A Case of Severe Seronegative Autoimmune Rhombencephalitis Successfully Treated with Rituximab
}

Farah Zarka' ${ }^{1}$ Tarik Slaoui ${ }^{2}$, Jean-Paul Makhzoum ${ }^{3}$

\author{
${ }^{1}$ Division of Internal Medicine, Hôpital du Sacré-Cour de Montréal, University of Montreal, Montreal, Quebec, Canada \\ ${ }^{2}$ Division of Neurology, Hôpital du Sacré-Cour de Montréal, University of Montreal, Montreal, Quebec, Canada \\ ${ }^{3}$ Division of Internal Medicine and Vasculitis Clinic, Hôpital du Sacré-Cour de Montréal, University of Montreal, Montreal, \\ Quebec, Canada \\ Author for correspondence: Jean-Paul Makhzoum: j.makhzoum@gmail.com \\ Received: 2 March 2019; Accepted after revision: 22 March 2020; Published: 26 March 2021. \\ DOI: https://dx.doi.org/10.22374/cjgim.v16i1.353
}

\begin{abstract}
Prompt treatment of autoimmune encephalitis can prevent long-term neurological sequelae. However, the data and evidence for the treatment of autoantibody negative encephalitis are limited, particularly so for rhombencephalitis. We report the case of a seronegative autoimmune rhombencephalitis successfully treated with rituximab.

A 21-year-old woman was transferred to our center for progressive neuropsychiatric symptoms and neurological deficits progressing into a Locked-in state despite first-line immunotherapy with corticosteroids and immunoglobulins. She was started on a rituximab induction protocol with noticeable improvement within days. The patient then received a maintenance dose and during a follow-up after 9 months was still in remission, suggesting that rituximab can be an efficient treatment for severe refractory seronegative rhombencephalitis
\end{abstract}

\section{RÉSUMÉ}

Un traitement rapide de l'encéphalite auto-immune peut prévenir les séquelles neurologiques à long terme. Cependant, les données et les preuves concernant le traitement de l'encéphalite séronégative sont limitées, en particulier pour la rhombencéphalite. Nous faisons état d'un cas de rhombencéphalite auto-immune séronégative traitée avec succès par le rituximab.

Une femme de 21 ans a été transférée dans notre centre pour des symptômes neuropsychiatriques progressifs et des déficits neurologiques progressant vers un état de blocage malgré une immunothérapie de première intention avec des corticostéroïdes et des immunoglobulines. Un protocole d'induction au rituximab a été entrepris et on a constaté une amélioration notable en quelques jours. La patiente a ensuite reçu une dose d'entretien et, après neuf mois de suivi, elle était toujours en rémission, ce qui permet de penser que le rituximab peut s’avérer un traitement efficace pour les rhombencéphalites séronégatives réfractaires graves. 


\section{Introduction}

Autoimmune encephalitis can be a morbid disease with a better long-term prognosis when treated promptly. ${ }^{1}$ Many advances have been made in the past decade with the discovery of antibody markers linked to specific syndromes, with seronegative autoimmune encephalitis being recognized as its own entity with established diagnostic criteria. ${ }^{2,3}$ Yet, data regarding its treatment and longterm follow-up is scarce. Treatment is often extrapolated from suggested protocols used in anti-NMDA receptor encephalitis, ${ }^{4}$ with first-line therapy consisting of high-dose corticosteroids, IV immunoglobulins, and plasma exchange. The second line of therapy usually consists of cyclophosphamide or rituximab. ${ }^{1}$ A more recent observational study provides some evidence for the use of rituximab as a second-line agent for autoantibody negative autoimmune limbic encephalitis; however, this study did not include patients with rhombencephalitis. ${ }^{5}$ We report the case of a 21-year-old woman with a severe case of seronegative autoimmune rhombencephalitis who was successfully treated with an induction and maintenance therapy of rituximab.

\section{Case presentation}

A 21-year-old Caucasian woman was transferred to our tertiary care center for progressive neurological symptoms. She had a known history of borderline personality disorder, substance abuse, and manic episodes. Two months prior to her arrival, the patient was hospitalized in our sister psychiatric hospital for manic behaviour with suicidal thoughts and had been started on an anti-psychotic regimen.

Over the course of her psychiatric hold, she developed progressive neurological symptoms of left brachial-facial hypoesthesia, diplopia, dysphagia, dysarthria, dysphonia, and ataxia. On arrival, the patient was afebrile, alert, and oriented. Her neurological exam was remarkable for apraxia, hypophonia, ophthalmoparesis, tetraparesis, severe dysmetria, and ataxia. Overall, she presented a clinical picture suggestive of rhombencephalitis.

Routine laboratory workup was normal. Head CT did not show any significant anomalies. Subsequent MRI highlighted deep white matter anomalies in the internal and external capsule, and in the periphery of the basal ganglia with restricted diffusion in the corona radiata and the internal capsule.

On day four, the patient's condition deteriorated. She was transferred to the ICU where she was started on a 5-day treatment of $1000 \mathrm{mg}$ of IV methylprednisolone (first-line immunotherapy, with no further glucocorticoids afterward), followed by 5 days of $20 \mathrm{~g}$ of IVIG with a presumptive diagnosis of autoimmune rhombencephalitis. Despite first-line therapy, the patient's condition declined with physical examination compatible with a Locked-in syndrome and imaging showing white matter anomalies extending to the pons and brachium pontis, and progression of signal-intensity anomalies in the corona radiata.

An extensive workup was done. Serological testing for connective tissue disease and vasculitis was normal with negative ANA, ENA, anti-DNA, ANCA, and C3-C4. Serum was negative for WNV (West Nile Virus), cryptolatex, HIV, syphilis, and borrelia burgdorferi. The patient also had normal TSH and negative thyroglobulin and anti-thyroglobulin antibody. Cerebrospinal fluid revealed oligoclonal bands and was negative for an infectious panel including bacterial cultures, mycoses, HSV, CMV, EBV, VZV, enterovirus, syphilis, and mycobacteria.

An autoimmune encephalitis antibody panel was unremarkable. This included negative anti-NMDA, anti-DPPX, anti-GABAB, VGKC, and AMPA-R profiles on both CSF and serum; negative neurological disease profile on CSF; and negative anti-Hu, anti-Yo, anti-Ri, anti-CV2, anti-PNMA2, and amphiphysin antibodies on serum. Total body scans did not show any suspicious lesions or teratomas. Multiple EEGs revealed nonspecific anomalies.

A diagnosis of seronegative rhombencephalitis was made. Rituximab $375 \mathrm{mg} / \mathrm{m}^{2}$ (550 mg) weekly was prescribed for 4 weeks, with the third and fourth infusions, respectively, being delayed by 5 days and 2 weeks due to persistent fever. Cyclophosphamide was considered, but not administered, due to the patient's young age and the risk of adverse effects (frail patient with recent fever of unknown origin and possible gonadal toxicity). Within days of the initial infusion, the patient showed signs of limb movement. Following the third session of treatment, neuroimaging revealed an overall improvement, characterized by decreased signalintensity anomalies and signs of inflammation. By the fourth rituximab infusion, she was verbally communicating and had regained significant motor function.

After a 3-month long hospitalization, the patient was discharged to a rehabilitation center. She still suffered from emotional lability and inappropriate behavior. Three months later, the patient was walking, talking, and eating, and by the 5 th month she had seemingly fully recuperated motor functions. The patient was then re-treated with a dose of $1000 \mathrm{mg}$ of rituximab to sustain her remission. Nearly 9 months following her discharge, no new lesions were documented on MRI. Overall, she has made a remarkable recovery but remains with residual neuropsychiatric symptoms.

\section{Discussion}

Autoimmune encephalitis can present as a wide range of acute or subacute symptoms. Our patient initially had isolated neuropsychiatric symptoms slowly progressing to signs of brain stem involvement and then to a Locked-in state. This distinctive presentation of autoantibody negative autoimmune encephalitis 
proved to be challenging, since a literature review of its treatment highlighted the lack of evidence and standardized practices for induction and maintenance therapy.

Our patient was treated with intravenous methylprednisolone and immunoglobulins while awaiting antibody markers. The treatment was based on protocols for anti-NMDA receptor encephalitis, which include first-line therapy of high-dose corticosteroids, plasmapheresis, and IVIG. These are based on class IV level of evidence, and no study has demonstrated the benefit of one therapy over the other. ${ }^{6}$ Thus, varying practices are observed between establishments. Second-line immunotherapy usually consists of rituximab and cyclophosphamide, but the time lapse between first- and second-line treatment is not well established, with varying expert opinion. ${ }^{7}$ Given the refractory nature of her condition, our patient received an induction treatment of rituximab 7 weeks after her initial presentation. A 2016 observational case-control study that included antibody positive and negative patients demonstrated that rituximab was an effective induction agent for both populations with potential advantages of subsequent monthly infusions, but no Locked-in syndrome was documented. ${ }^{5}$

To the best of our knowledge, this is the first published case of seronegative autoimmune rhombencephalitis successfully treated with rituximab as a second-line agent. Our patient achieved remission with a standard induction treatment of $375 \mathrm{mg} / \mathrm{m}^{2}$ weekly for 4 weeks, followed 5 months later by a maintenance dose of $1000 \mathrm{mg}$. The diagnosis of autoantibody negative rhombencephalitis was based on the Neurology Lancet criteria. Most antibodies were tested on CSF for optimal wield. Anti-Hu, anti-Yo, anti-Ri, anti-CV2, and anti-PNMA2 antibodies were searched for only in serum. However, these are mainly paraneoplastic ${ }^{8,9}$ with imaging showing no signs of any thoracic, abdominal, or pelvic masses.

\section{Conclusion}

This case suggests rituximab is an effective agent for the treatment of severe autoantibody negative rhombencephalitis. Longer term follow-up is necessary to assess functional prognosis, risk of relapse, and the need for subsequent maintenance infusions of rituximab.

\section{References}

1. Titulaer MJ, McCracken L, Gabilondo I, et al. Treatment and prognostic factors for long-term outcome in patients with anti-NMDA receptor encephalitis: An observational cohort study. Lancet Neurol. 2013;12(2): 157-65. http://dx.doi.org/10.1016/S1474-4422(12)70310-1

2. Antoine J. Autoimmune encephalitis: Paving the way for early diagnosis. Lancet Neurol. 2016;15(4):349-50. http://dx.doi.org/10.1016/ S1474-4422(16)00025-9

3. Graus F, Titulaer MJ, Balu R, et al. A clinical approach to diagnosis of autoimmune encephalitis. Lancet Neurol. 2016;15(4):391-404. http://dx.doi .org/10.1016/S1474-4422(15)00401-9

4. Dalmau J, Lancaster E, Martinez-Hernandez E, et al. Clinical experience and laboratory investigations in patients with anti-NMDAR encephalitis. Lancet Neurol. 2011;10(1):63-74. http://dx.doi.org/10.1016/S1474-4422(10)70253-2

5. Lee W-J, Lee S-T, Byun J-I, et al. Rituximab treatment for autoimmune limbic encephalitis in an institutional cohort. Neurology. 2016;86(18):1683-91. http://dx.doi.org/10.1212/WNL.0000000000002635

6. Bartolini, L. Practice current: How do you treat anti-NMDA receptor encephalitis? Neurol Clin Pract. 2016;6(1):69-72. http://dx.doi.org/10.1212/ CPJ.0000000000000219

7. Lancaster E. The diagnosis and treatment of autoimmune encephalitis. J Clin Neurol. 2016;12(1):1-13. http://dx.doi.org/10.3988/jcn.2016.12.1.1

8. Alamowitch S, Graus F, Uchuya M, et al. Limbic encephalitis and small cell lung cancer: Clinical and immunological features. Brain. 1997;120(6): 923-928. http://dx.doi.org/10.1093/brain/120.6.923

9. Dalmau J, Graus F, Villarejo A, et al. Clinical analysis of anti-Ma2-associated encephalitis. Brain. 2004;127(8):1831-44. http://dx.doi.org/10.1093/brain/ awh203 


\title{
Rheumatoid Vasculitis Following Change to Naturopathic Remedies
}

\author{
Graeme Prosperi-Porta, MD MASc, Ben John Wilson, MD
}

Department of Medicine, Cumming School of Medicine, University of Calgary, Calgary, AB, Canada Adresse pour correspondance: Graeme Prosperi-Porta: Email: Graeme.prosperiporta@ucalgary.ca Received: 27 March 2020; Accepted: 27 April 2020; Published: 26 March 2021.

DOI: http://dx.doi.org/10.22374/cjgim.v16i1.439

A 66-year-old female with seropositive rheumatoid arthritis (RA) complicated by cutaneous and pulmonary nodules presented to hospital with progressive painful black discoloration on the plantar aspect of her right great toe (Figure 1). Five months prior, she had discontinued sulfasalazine, methotrexate, hydroxychloroquine, and infliximab due to medication-attributed side effects in favor of naturopathy. Podiatric surgery performed a great toe amputation through the first metatarsal head for a diagnosis of "gangrene" without further investigations.

Two weeks later, the patient returned with bilateral foot pain and new multifocal, painless raised fluid-filled black lesions on her toes and distal forefeet, and a black ulceration medioproximal to the amputation site (Figure $2 \mathrm{~A}-\mathrm{B}$ ). She also complained of a one-month history of bilateral foot drop. She had no Reynaud's phenomenon, was afebrile, and had a leukocyte count of $7.7 \times$

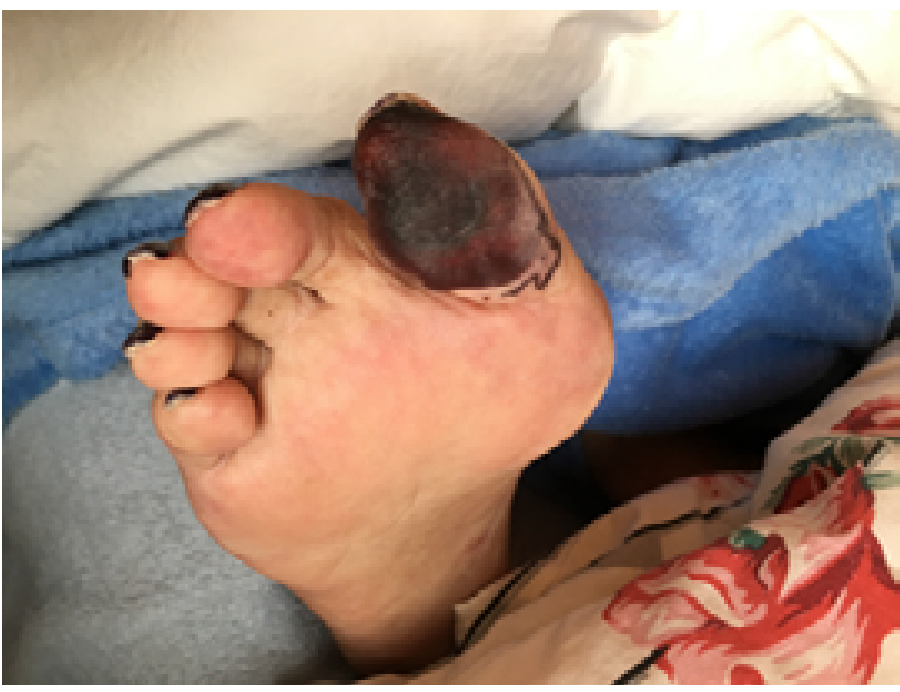

Figure 1. Right great toe on first hospital visit diagnosed as "gangrene."
$10 \mathrm{E} 9 / \mathrm{L}(4.0-11.0 \times 10 \mathrm{E} 9 / \mathrm{L})$, with negative blood and urine cultures. Her rheumatoid factor was $2020 \mathrm{kU} / \mathrm{L}(0-20 \mathrm{kU} / \mathrm{L})$ and anti-cyclic citrullinated peptide was $178.5 \mathrm{U} / \mathrm{mL}(0-4.9$ $\mathrm{U} / \mathrm{mL}$ ). Her anti-nuclear antibody, C3, C4 cryoglobulin, and ANCA levels were unremarkable. Human immunodeficiency virus, hepatitis $B$, and hepatitis $C$ were negative. Transesophageal echocardiography showed no valvular vegetation and computed tomography angiography showed mild diffuse vascular disease without proximal lesions or polyarteritis nodosa. Electromyography showed a severe length-dependent sensorimotor axonal polyneuropathy consistent with mononeuritis multiplex. She was diagnosed with rheumatoid vasculitis.

Despite three intravenous doses of methylprednisolone $1 \mathrm{~g}$, two doses of intravenous rituximab $1 \mathrm{~g}$, and twice-daily oral sulfasalazine $1 \mathrm{~g}$, she underwent bilateral transmetatarsal amputations for disease progression. No histologic examination was performed as the diagnosis was confirmed clinically and biochemically.

Rheumatoid vasculitis, a severe extra-articular manifestation of RA, is predominantly seen in longstanding seropositive RA with other extra-articular manifestations. ${ }^{1}$ High serum rheumatoid factor and anti-cyclic citrullinated peptide are associated with RA vasculitis. ${ }^{2}$ While its incidence has decreased in the modern therapeutic era from 9.1 to 3.9 cases per million in 1998-2000 to 2000-2010, respectively, rheumatoid vasculitis has a 5-year mortality between 30 and $60 \%$ from organ involvement and treatment complications. ${ }^{1-3}$

If RA vasculitis was considered during the patient's initial presentation for "gangrene," early immunosuppression may have prevented disease progression requiring bilateral transmetatarsal amputations. This case reminds clinicians to consider vasculitis in any RA patient with new skin findings and to strongly dissuade patients from pursuing only naturopathic remedies, 


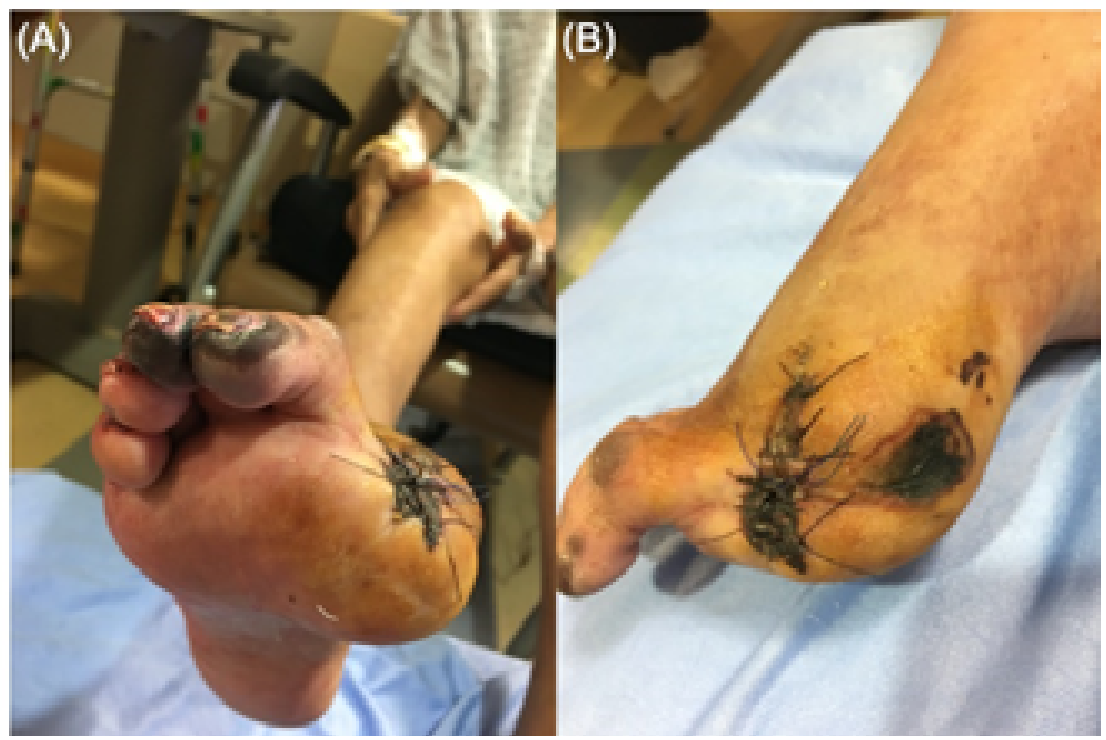

Figure 2. Right foot following great toe amputation showing (A) distal foot and (B) postsurgical site.

as disease-modifying medical therapies have been shown to prevent RA complications such as vasculitis. ${ }^{4}$

\section{Competing Interests}

The authors declare that they have no financial or nonfinancial competing interests related to this case report.

\section{Funding}

There is no funding associated with this case report.

\section{Author's Contributions}

GPP and BW were involved directly in diagnosis and patient care. GPP and BW prepared the manuscript. All authors read and approved the final manuscript.

\section{References}

1. Bartels CM, Bridges AJ. Rheumatoid vasculitis: Vanishing menace or target for new treatments? Curr Rheumatol Rep. 2010;12(6):414-19. http://dx.doi. org/10.1007/s11926-010-0130-1

2. Turesson C, Jacobsson LT, Sturfelt G, Matteson EL, Mathsson L, Ronnelid J. Rheumatoid factor and antibodies to cyclic citrullinated peptides are associated with severe extra-articular manifestations in rheumatoid arthritis. Ann Rheum Dis. 2007;66(1):59-64. http://dx.doi.org/10.1136/ ard.2006.054445

3. Ntatsaki E, Mooney J, Scott DG, Watts RA. Systemic rheumatoid vasculitis in the era of modern immunosuppressive therapy. Rheumatology (Oxford). 2014;53(1):145-52. http://dx.doi.org/10.1093/rheumatology/ket326

4. Singh JA, Saag KG, Bridges SL, Jr., Akl EA, Bannuru RR, Sullivan MC, et al. 2015 American College of Rheumatology guideline for the treatment of rheumatoid arthritis. Arthritis Care Res (Hoboken). 2016;68(1):1-25. http:// dx.doi.org/10.1002/acr.22783 